\title{
Lymphopenia as a Potential Predictor of Ipsilateral Breast Tumor Recurrence in Early Breast Cancer
}

\author{
OYEON CHO ${ }^{1}$, MISON CHUN ${ }^{1}$, SANG WON KIM $^{2}$, YONG SIK JUNG ${ }^{3}$ and HYUNEE YIM ${ }^{4}$ \\ ${ }^{1}$ Department of Radiation Oncology, Ajou University School of Medicine, Suwon, Republic of Korea; \\ ${ }^{2}$ Department of Radiation Oncology, Konyang University School of Medicine, Daejeon, Republic of Korea; \\ ${ }^{3}$ Department of Surgery, Ajou University School of Medicine, Suwon, Republic of Korea; \\ ${ }^{4}$ Department of Pathology, Ajou University School of Medicine, Suwon, Republic of Korea
}

\begin{abstract}
Background/Aim: The aim of this study was to investigate the association between lymphopenia after breast conserving therapy $(B C T)$ and ipsilateral breast tumor recurrence (IBTR) in early breast cancer (EBC). Patients and Methods: We examined 216 EBC patients treated with partial mastectomy followed by radiotherapy $(R T)$, none of whom received chemotherapy. Absolute lymphocyte counts (ALCs) during the two years after RT were collected from each patient: pretreatment $A L C, A L C$ at 3-5 months (ALC1), $A L C$ at 9-11 months, ALC at 15-17 months, and ALC at 2123 months. Results: The 102 patients with ALC1 $\leq 1,479$ cells/ul (defined as lymphopenia) had significantly higher 10-year IBTR rate than the 102 patients with ALC1 >1,479 cells/ $\mu l(16.2 \%$ vs. $1 \%, p=0.0034)$. The multivariate analysis showed that age, resection margins, human epidermal growth factor receptor, and lymphopenia were significant predictors of IBTR. Conclusion: Lymphopenia is a potential predictor for IBTR in EBC patients treated with $B C T$.
\end{abstract}

Breast conserving therapy (BCT), including breast conserving surgery (BCS) followed by whole breast radiotherapy (WBRT), has been an alternative to mastectomy for early breast cancer (EBC) patients. Early randomized trials comparing BCT with mastectomy support this approach, as no differences in recurrence and survival have been observed between patients undergoing BCT and mastectomy (1-6). However, a higher local recurrence rate was observed after BCT than after mastectomy

This article is freely accessible online.

Correspondence to: Oyeon Cho, Department of Radiation Oncology, Ajou University School of Medicine, 164 World cup-ro, Yeongtong-gu, Suwon 16499, Republic of Korea. Tel: +82 0312195884, Fax: +82 0312195894, e-mail: oyeoncho@ajou.ac.kr

Key Words: Breast cancer, lymphopenia, tumor recurrence, risk factors.
(BCT 3-22\% vs. mastectomy: 2-14\%). Specifically, the rate of ipsilateral breast tumor recurrence (IBTR) after BCT in EBC patients was approximately $10 \%$ in a 10 -year period (7). Diagnostic modalities, such as magnetic resonance imaging (MRI) and positron emission tomography-computed tomography (PET-CT), providing information regarding surgical resection margins (RMs), effective systemic therapy, and tumor bed (TB) boost have contributed to a reduction in the IBTR rate to $2 \%$ within 5 years, equivalent to the outcomes observed following mastectomy $(8,9)$. However, IBTR is still observed after BCT, suggesting the presence of unknown risk factors.

Radiation-related lymphopenia (RRL) affects clinical outcomes of patients with various cancers (10), most of which are aggressive or at an advanced stage, including glioblastoma, small cell lung cancer, and locally advanced pancreatic cancer. However, the association between RRL and clinical outcomes of EBC patients remains unexplored, likely owing to the unpredictable influence of various chemotherapy (CTx) regimens, dosages, and individual RT fields on the reduction in absolute lymphocyte counts (ALCs) (11). Therefore, we aimed to investigate the association between lymphopenia after BCT and IBTR in EBC patients who did not receive CTx.

\section{Patients and Methods}

This study was approved by the Institutional Review Board (AJIRBMED-MDB-18-549). We examined 216 EBC patients treated with BCT from 2004 to 2012 at Ajou University School of Medicine. Male patients with breast cancer; those treated with adjuvant or neoadjuvant CTx; those with missing immunohistochemistry (IHC) data on the expression of estrogen receptors (ER), progesterone receptors (PR), and human epidermal growth factor receptor 2 (HER2); those with synchronous bilateral breast cancer; and those without follow up data were excluded. All patients were newly diagnosed and underwent both a lumpectomy and axillary evaluation followed by WBRT. Their cancers were staged as IA-IIB, according to the seventh edition of the American Joint Committee on Cancer guidelines. Most patients with ER or PR positive tumors received adjuvant endocrine therapy such as tamoxifen (+/gonadotropin releasing hormone $[\mathrm{GnRH}]$ agonist) or aromatase 
Table I. Characteristics of 216 patients treated with breast conserving therapy and their absolute lymphocyte counts.

\begin{tabular}{|c|c|}
\hline Characteristics & $\begin{array}{c}\mathrm{N}(\%) \text { or } \\
\text { median } \\
\text { (Interquartile } \\
\text { range) }\end{array}$ \\
\hline Age at diagnosis, years & $48(43-54)$ \\
\hline$\leq 40$ & $79(37)$ \\
\hline$>40$ & $137(63)$ \\
\hline \multicolumn{2}{|l|}{ Laterality } \\
\hline Left & $104(48)$ \\
\hline Right & $112(52)$ \\
\hline \multicolumn{2}{|l|}{ Multifocality } \\
\hline Single tumor & $203(94)$ \\
\hline Multiple tumors & $13(6)$ \\
\hline \multicolumn{2}{|l|}{ Pathology } \\
\hline Invasive ductal carcinoma & $186(86)$ \\
\hline Non-invasive ductal carcinoma & $30(14)$ \\
\hline \multicolumn{2}{|l|}{ T stage } \\
\hline $1 \mathrm{mi}$ & $15(7)$ \\
\hline $1 \mathrm{a}$ & $25(12)$ \\
\hline $1 b$ & $85(39)$ \\
\hline $1 \mathrm{c}$ & $82(38)$ \\
\hline 2 & $9(4)$ \\
\hline \multicolumn{2}{|l|}{$\mathrm{N}$ stage } \\
\hline 0 & $210(97)$ \\
\hline 1 & $6(3)$ \\
\hline \multicolumn{2}{|l|}{ Estrogen receptor (ER) expression } \\
\hline Positive & $192(89)$ \\
\hline Negative & $24(11)$ \\
\hline \multicolumn{2}{|l|}{ Progesterone receptor (PR) expression } \\
\hline Positive & $182(84)$ \\
\hline Negative & $24(16)$ \\
\hline \multicolumn{2}{|l|}{$\begin{array}{l}\text { Human epidermal growth receptor } 2 \\
\text { (HER2) expression }\end{array}$} \\
\hline Positive & $34(13)$ \\
\hline Negative & $182(87)$ \\
\hline \multicolumn{2}{|l|}{ Subtype } \\
\hline Luminal (ER or PR+, HER2-) & $179(83)$ \\
\hline Luminal-HER2 (ER or PR+, HER2+) & $18(8)$ \\
\hline HER2 (ER-, PR-, HER2+) & $11(5)$ \\
\hline Triple negative (ER-, PR-, HER2-) & $8(4)$ \\
\hline \multicolumn{2}{|c|}{ Tamoxifen or aromatase inhibitor administration } \\
\hline Yes & $196(91)$ \\
\hline No & $20(9)$ \\
\hline \multicolumn{2}{|l|}{ Histologic grade } \\
\hline 1 & $80(37)$ \\
\hline 2 & $74(34)$ \\
\hline 3 & $37(17)$ \\
\hline Information not available & $25(12)$ \\
\hline \multicolumn{2}{|l|}{ Intraductal component } \\
\hline Present & $167(77)$ \\
\hline Absent & $47(22)$ \\
\hline Information not available & $2(1)$ \\
\hline \multicolumn{2}{|l|}{ Resection margin status } \\
\hline Invasive carcinoma positive & $11(5)$ \\
\hline In situ carcinoma positive & $19(9)$ \\
\hline Negative & $186(86)$ \\
\hline Total radiation dose, Gy & $59(55-59)$ \\
\hline$\leq 59$ & $203(94)$ \\
\hline$>59$ & $13(6)$ \\
\hline
\end{tabular}

\begin{tabular}{lc}
\hline $\begin{array}{l}\text { Absolute lymphocyte } \\
\text { count (ALC), cells/ } \mu 1\end{array}$ & $\begin{array}{c}\text { Median } \\
\text { (Interquartile range), N }\end{array}$ \\
\hline Pretreatment ALC (ALC0) & $1847(1545-2308), 215$ \\
ALC 3-5 months after radiotherapy (ALC1) & $1479(1212-1744), 204$ \\
ALC 9-11 months after radiotherapy (ALC2) & $1626(1348-1927), 202$ \\
ALC 15-17 months after radiotherapy (ALC3) & $1730(1434-2040), 207$ \\
ALC 21-23 months after radiotherapy (ALC4) & $1855(1595-2245), 200$ \\
\hline
\end{tabular}

inhibitor (AI) according to their menopausal status for five years. No patient with HER2 positivity received trastuzumab. Patients were followed up every 6 months for the first 5 years and every 12 months thereafter. During follow up, patients received a physical examination, mammography, breast ultrasonography (US), bone scan, and abdominal US every 6 months and chest CT with contrast (or PET-CT) every 12 months. The end point of this study was IBTR and the median follow up was 83 months (range $=15-174$ months). Events of regional recurrence (RR) at the ipsilateral axillary, supraclavicular, or internal mammary lymph nodes (LN), distant metastasis (DM), asynchronous contralateral breast recurrence (CBR), and disease-specific death (DSD) were recorded separately.

External beam RT was delivered to the whole breast with a median dose of 45 Gy in 25 fractions using a tangential field, with a boost dose to the TB. When electron beam was used, the median was $14 \mathrm{~Gy}$ in 7 fractions. The total dose was defined as the sum of the WBRT and boost doses. The duration between the operation and RT initiation was a median of 4 weeks.

Information was obtained regarding histologic grade (HG), presence of intraductal components, RM status, and ER, PR, and HER2 positivity from the pathologic reports of each patient. HG was reported according to the Nottingham Histologic Score system; however, small lesions less than $1 \mathrm{~mm}$ were not included. RM negativity was defined as a margin at a distance of at least $1 \mathrm{~mm}$ from the tumor, while margins at a distance less than $1 \mathrm{~mm}$ from the tumor were considered RM positive. This definition was applied to invasive carcinomas and intraductal carcinomas. The four molecular subtypes were luminal (ER+ or PR+, HER2-), luminalHER2 (ER+ or PR+, HER2+), HER2 (ER-, PR-, and HER2+), and triple negative (TN) (ER-, PR-, and HER2-). HER2+ tumors were defined as those with an IHC score of $3+$ or $2+$, with gene amplification examined via fluorescent in situ hybridization (FISH). If IHC scores were 2+ and FISH analysis data were unavailable, we considered the tumors as HER-. Peripheral ALCs at different stages during the two years after RT were collected from each patient: pretreatment ALC (ALC0), ALC at 3-5 months (ALC1), ALC at 911 months (ALC2), ALC at 15-17 months (ALC3), and ALC at 2123 months (ALC4).

At first, we selected the ALC with the largest area under the curve (AUC) among candidate ALCs for predicting IBTR using receiver operating characteristics (ROC) curves. In the 14 patients who experienced IBTR, we examined recurrence time, age at diagnosis, the selected ALC, tumor pathology, presence of intraductal components, T stage, RM status, total dose administered, 

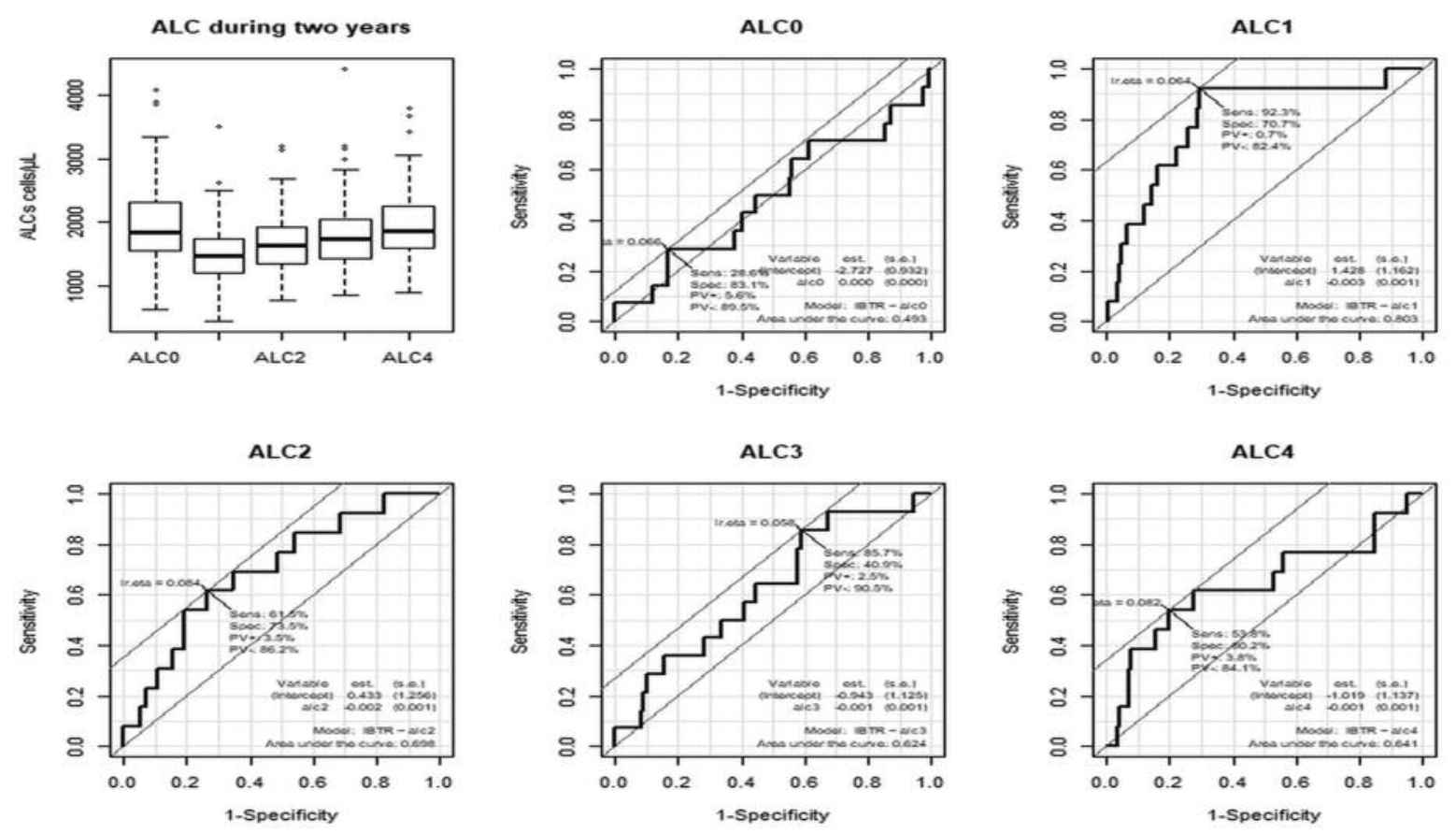

Figure 1. Boxplot of pretreatment ALC (ALCO), ALC at 3-5 months (ALC1), ALC at 9-11 months (ALC2), ALC at 15-17 months (ALC3), and ALC at 21-23 months (ALC4) after radiotherapy, and receiver operating characteristics curves of the five groups for predicting ipsilateral breast tumor recurrence. ALC: Absolute lymphocyte count.

and surrogate molecular subtype. We also examined whether these patients experienced a true recurrence (TR) or whether they developed a new primary (NP) tumor, based on the histologic type, ER, and location of the secondary tumor (12). Age, HER2 positivity, RM status, IBTR, RR, DM, CBR, and DSD were then compared between the two groups (classified based on the median value of the selected ALC: 1479 cells/ $\mu$ l) using the Fisher's exact test or the Chisquare test. Differences in cumulative IBTR rates between patients with low ALCs and those with high ALCs were compared using Kaplan-Meier plots and log rank tests. A Cox proportional hazard model was used to compare age, HER2 positivity, and RM with selected ALCs through a multivariate analysis. Two-sided $\mathrm{p}$ values less than 0.05 were considered statistically significant. All statistical analyses were performed using R software version 3.5.2 (the R foundation for Statistical Computing, http://www.r-project.org).

\section{Results}

Table I shows the clinical characteristics of the patients and ALCs for a two-year period following RT. Six patients with axillary LN (ALN) metastasis, including one with sentinel LN microscopic metastasis and five with single metastasis observed after the dissection of 7-24 ALNs, were identified; molecularly, they all had luminal type of breast cancer. Overall, 196 of 197 patients who were ER+ or PR+ received systemin endocrine therapy, and of these, 114 were treated with tamoxifen with or without a GnRH agonist, whereas the others received AIs. The duration of administration was a median of 60 months (interquartile range $=58-61$ months). A decline in ALC was observed after BCT, but there was a tendency for complete recovery by ALC4 after a nadir at ALC1. Among the ALCs at various stages, ALC1 was associated with the largest AUC (0.803) for predicting IBTR during the two years following RT (Figure 1). The sensitivity and specificity for this prediction were $92.3 \%$ and $70.7 \%$, respectively.

Overall, 14 patients underwent IBTR, and two of them experienced relapse in the contralateral breast asynchronously, without any other events. Three patients experienced recurrence in the ipsilateral supraclavicular LN (SCL), ALN/SCL, and ALN. Overall, four patients developed metastases: one showed metastasis to the liver and mediastinal LN, one to the liver and lung, and two to the bone and lung. All patients with metastasis eventually died. One of them experienced RR before DM, and one experienced both RR and DM simultaneously. The 5- and 10-year IBTR (5IBTR and 10IBTR) were $2.4 \%$ and $10.1 \%$, respectively, whereas the disease-free survival rate was $98.6 \%$ at 5 years and $98 \%$ at 10 years.

Table II describes the relapse type (TR or NP), factors affecting IBTR, and ALC1 according to the time-point of the event among the 14 patients who experienced IBTR. All events occurred in patients aged $\leq 50$ years and half of them were $\geq 40$ years old. Low ALC1, the presence of intraductal 

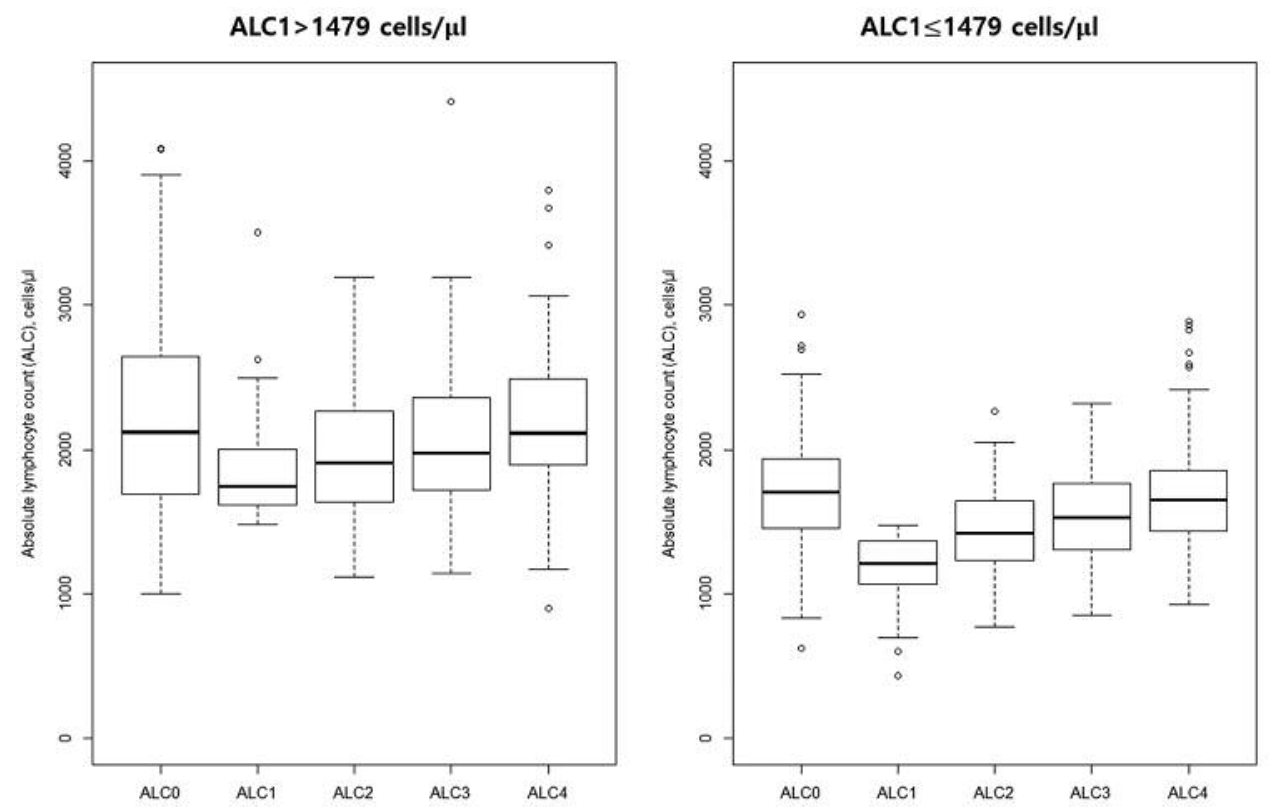

Figure 2. Changes in pretreatment ALC (ALCO), ALC at 3-5 months (ALC1), ALC at 9-11 months (ALC2), ALC at 15-17 months (ALC3), and ALC

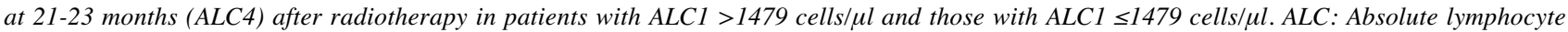
count.

Table II. Details of 14 patients who experienced ipsilateral breast tumor recurrence after breast conserving treatment.

\begin{tabular}{|c|c|c|c|c|c|c|c|c|c|c|}
\hline No & $\begin{array}{c}\text { Event, } \\
\text { years }\end{array}$ & $\mathrm{TR} / \mathrm{NP}^{\dagger}$ & $\begin{array}{l}\text { Age, } \\
\text { years }\end{array}$ & $\begin{array}{l}\text { ALC1, } \\
\text { cells/ } \mu 1\end{array}$ & Pathology & $\begin{array}{l}\text { Intraductal } \\
\text { component }\end{array}$ & $\mathrm{T}$ stage & RM & $\begin{array}{l}\text { RT dose, } \\
\text { Gy }\end{array}$ & Subtype \\
\hline 1 & 2.0 & TR & 33 & 2048 & IDC & Present & $1 \mathrm{mi}$ & DCIS+ & 63 & HER2 \\
\hline 2 & 2.4 & TR & 49 & 1138 & IDC & Present & $1 \mathrm{c}$ & Negative & 59 & HER2 \\
\hline 3 & 3.8 & TR & 46 & 1312 & IDC & Present & $1 \mathrm{mi}$ & Negative & 59 & Luminal-HER2 \\
\hline 4 & 4.2 & $\mathrm{TR}$ & 39 & 1300 & Mucinous & Present & $1 \mathrm{~b}$ & Negative & 59 & Luminal \\
\hline 5 & 4.7 & NP & 50 & 1113 & IDC & Present & $1 \mathrm{a}$ & Negative & 59 & Luminal-HER2 \\
\hline 6 & 5.8 & $\mathrm{TR}$ & 40 & 604 & IDC & Present & $1 \mathrm{mi}$ & Negative & 55 & Luminal \\
\hline 7 & 6.0 & $\mathrm{NP}$ & 37 & 878 & IDC & Present & $1 \mathrm{~b}$ & IDC+ & 65 & Luminal \\
\hline 8 & 6.3 & NP & 43 & 1082 & IDC & Present & $1 \mathrm{~b}$ & DCIS+ & 59 & HER2 \\
\hline 9 & 7.3 & NP & 45 & 1210 & IDC & Present & $1 b$ & Negative & 59 & Luminal \\
\hline 10 & 7.6 & NP & 37 & 1231 & IDC & Present & $1 \mathrm{a}$ & Negative & 59 & Luminal \\
\hline 11 & 7.8 & NP & 41 & 902 & IDC & Present & $1 \mathrm{mi}$ & Negative & 59 & HER2 \\
\hline 12 & 7.8 & TR & 26 & 992 & IDC & Present & $1 \mathrm{c}$ & DCIS+ & 59 & Luminal \\
\hline 13 & 8.8 & $\mathrm{TR}$ & 37 & NA & IDC & Present & $1 b$ & Negative & 59 & Luminal-HER2 \\
\hline 14 & 13.8 & TR & 50 & 924 & IDC & Present & $1 b$ & DCIS+ & 62 & Luminal \\
\hline
\end{tabular}

LR: Local recurrence; TR: true recurrence; NP: new primary tumor; ALC: absolute lymphocyte count; RT: radiotherapy; ALC1: ALC 3-5 months after RT; RM: resection margin; ER: estrogen receptor; PR: progesterone receptor, HER2: human epidermal growth receptor 2; AI: aromatase inhibitor; NA: information not available. †TR/NP was decided based on classification according to histologic type, ER, and location.

components, positive RM in invasive ductal carcinoma (IDC) or ductal carcinoma in situ (DCIS), and HER2 positivity were observed in 14 patients with IBTR. The non-lymphopenia group (patients with ALC1 $>1479$ cells $/ \mu \mathrm{l}$ ) and the lymphopenia group (patients with ALC1 $\leq 1479$ cells/ $\mu$ l) showed a significant difference in IBTR (Table III). The non- lymphopenia group had a higher median ALC0, ALC2, ALC3, and ALC4 than the lymphopenia group (Figure 2). Further, the cumulative incidence of IBTR was significantly higher in the lymphopenia group than in the non-lymphopenia group (Figure 3). The difference in 5IBTR and 10IBTR between the non-lymphopenia group and lymphopenia group 
was greater when only patients aged $\leq 50$ years were considered (5IBTR: $1.7 \%$ vs. $5.8 \%$, 10IBTR: $1.7 \%$ vs. $23.2 \%$ $p=0.004)$ than when all patients were considered (5IBTR: $1 \%$ vs. $4 \%$, 10IBTR: $1 \%$ vs. $16.2 \% p=0.0034)$. The multivariate analysis showed that age $\leq 40$ years, positive RM, HER2 positivity, and ALC1 $\leq 1479$ cells/ $\mu$ l were significant predictors of IBTR (Table IV).

\section{Discussion}

This study suggests that lymphopenia after BCT is associated with IBTR in EBC patients. This study aspired to exclude influencing factors associated with cytotoxic CTx, lymphocyte count, and IBTR, and to include only patients with a low tumor burden who were treated with WBRT. Past studies regarding treatment-related lymphopenia have included patients with aggressive or advanced carcinoma who received both RT and CTx during treatment. In these patients, a poor prognosis may have resulted from immune system effects, including lymphopenia and its interference with the cancer. Treatment-related lymphopenia and the lack of an individual's ability to overcome it can also negatively influence clinical outcomes. Therefore, our study has been able to eliminate confounders, thus providing clearer results.

ALC1 was used as a critical point to identify lymphopenia due to its excellent ability to predict IBTR (AUC>0.8). ALC1 was the nadir following BCT, and a two-year duration was needed for ALC recovery. ALC0, ALC2, ALC3, and ALC4 also tended to be higher in the non-lymphopenia group than in the lymphopenia group. This observation of low ALCs for a long duration following RT and the clinical impact of their nadir is similar to that in past studies on glioblastoma and pancreatic cancer $(13,14)$. However, in the present study, lymphopenia mainly occurred due to RT, whereas the administration of CTx, the use of varying RT fields depending on disease extent, and the high proportion of incompletely resected aggressive tumors may have had a greater influence on lymphopenia in past studies. In our study, the ALC1 after WBRT for EBC was approximately $20 \%$ lower than the pretreatment ALC, whereas a reduction of more than $50 \%$ was observed in past reports on two aggressive cancers. CTx can induce lymphopenia; however, its regimen- and dosage-dependent effect on lymphocytes and lymphocyte subpopulations is not clear. Therefore, the current approach of examining EBC patients treated with WBRT without CTx is valid for evaluating lymphopenia as an individual immunity. Moreover Sage et al. reported that lymphocytes included more CD4+ and regulatory $\mathrm{T}$ cells in breast cancer patients treated with RT without CTx than in those treated with CTx (11). This suggests that the analysis of ALCs in breast cancer patients treated with RT without CTx may reflect anti-tumor immunity better than an analysis of patient undergoing a treatment regimen that includes CTx.
Table III. Comparison of risk factors and treatment results between nonlymphopenia and lymphopenia groups.

\begin{tabular}{|c|c|c|c|}
\hline & $\begin{array}{l}\text { Non-lymphopenia } \\
\text { group }\end{array}$ & $\begin{array}{l}\text { Lymphopenia } \\
\text { group }\end{array}$ & \\
\hline & $\begin{array}{c}\text { ALC1>1479 } \\
\text { cells } / \mu 1 \\
\mathrm{~N}=102\end{array}$ & $\begin{array}{c}\mathrm{ALC} 1 \leq 1479 \\
\text { cells/ } \mu 1 \\
\mathrm{~N}=102\end{array}$ & \\
\hline Variables & $\mathrm{N}(\%)$ & $\mathrm{N}(\%)$ & $p$-Value \\
\hline Age, years & & & 1 \\
\hline$\leq 40$ & $19(19)$ & $20(20)$ & \\
\hline$>40$ & $83(81)$ & $82(80)$ & \\
\hline $\begin{array}{l}\text { Human epidermal } \\
\text { growth receptor } 2\end{array}$ & & & 0.2 \\
\hline Positive & $9(9)$ & $16(16)$ & \\
\hline Negative & $93(91)$ & $86(84)$ & \\
\hline Resection margin & & & 0.839 \\
\hline Positive & $13(13)$ & $15(15)$ & \\
\hline Negative & $89(87)$ & $87(85)$ & \\
\hline Ipsilateral breast & & & \\
\hline tumor recurrence & & & 0.006 \\
\hline True recurrence & $1(1)$ & $6(6)$ & \\
\hline New primary & $0(0)$ & $6(6)$ & \\
\hline No & $101(99)$ & $90(88.2)$ & \\
\hline $\begin{array}{l}\text { Regional lymph } \\
\text { node recurrence }\end{array}$ & & & 1 \\
\hline Yes & $1(1)$ & $2(2)$ & \\
\hline No & $101(99)$ & $100(98)$ & \\
\hline Distant metastasis & & & 1 \\
\hline Yes & $2(2)$ & $2(2)$ & \\
\hline No & $100(98)$ & $100(98)$ & \\
\hline $\begin{array}{l}\text { Contralateral breast } \\
\text { recurrence }\end{array}$ & & & 1 \\
\hline Yes & $2(2)$ & $2(2)$ & \\
\hline No & $100(98)$ & $100(98)$ & \\
\hline Disease-specific death & & & 1 \\
\hline Yes & $2(2)$ & $2(2)$ & \\
\hline No & $100(98)$ & $100(98)$ & \\
\hline
\end{tabular}

ALC1: Absolute lymphocyte count 3-5 months after radiotherapy.

An increase in the RT field size can influence lymphopenia in patients who undergo RT for solid tumors (15). Therefore, we can assume that the effects of radiation on circulating lymphocytes are comparable among the patients of this study, for whom radiation was delivered to the whole breast and TB at a constant dose using the same RT technique. Past reports have suggested that pretreatment lymphopenia in patients with advanced cancers is a prognostic factor for survival, which supports the conclusion that tumor-induced lymphopenia, preexisting immunosuppressive conditions, or combinations of both factors lead to poor clinical outcome (16). Recent reports regarding poor responses to immune checkpoint inhibitors in patients with lymphopenia support the conclusion that both factors may be associated with 

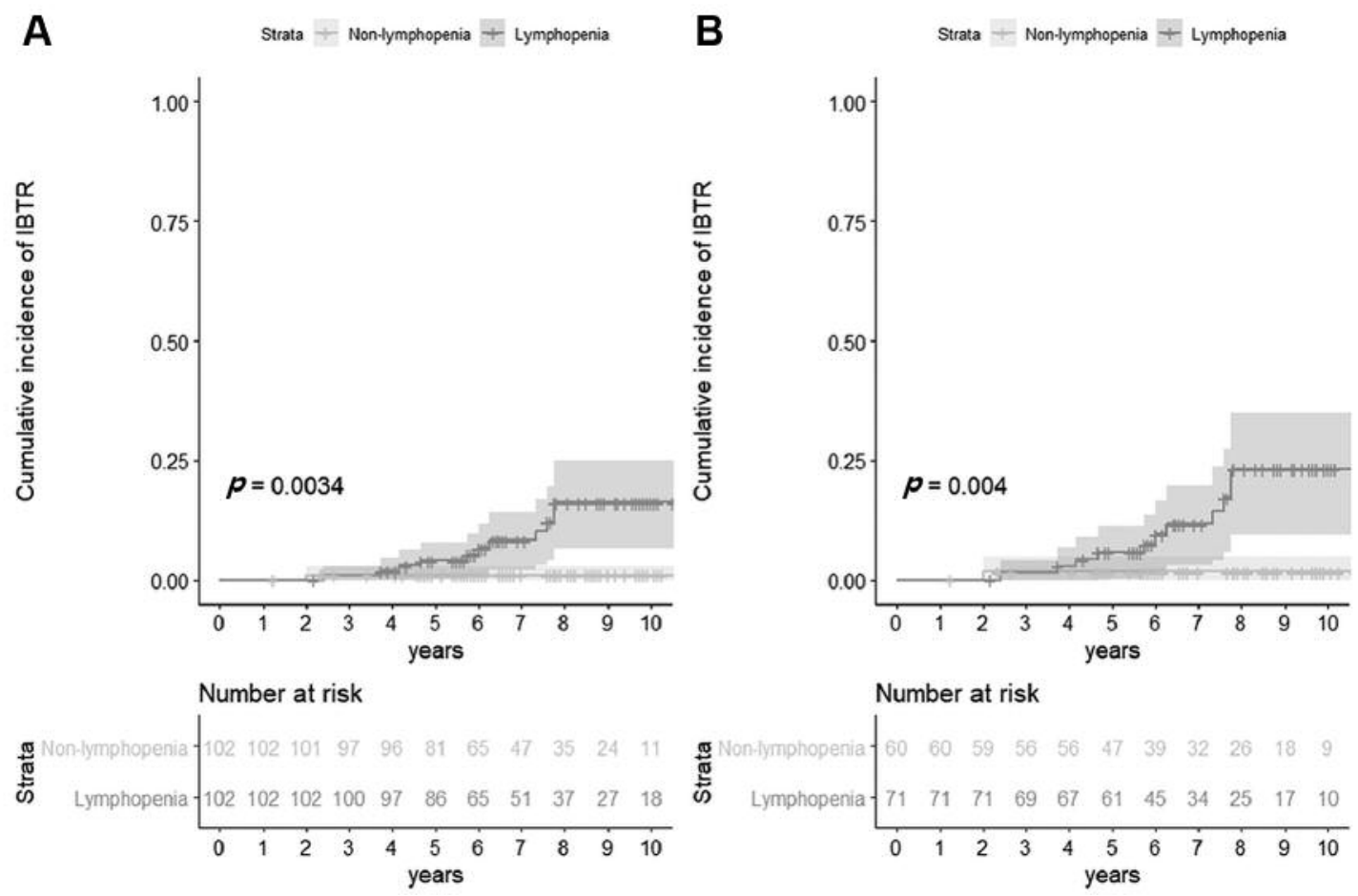

Figure 3. Cumulative incidence of ipsilateral breast tumor recurrence among patients with absolute lymphocyte counts at 2 months after radiotherapy (ALC1) >1,479 cells/ul (non-lymphopenia group) and those with ALC1 $\leq 1,479$ cells/ $\mu$ l (lymphopenia group). (A) Comparison in all patients and (B) comparison in patients aged $\leq 50$ years. ALC: Absolute lymphocyte count.

Table IV. Univariate analysis and multivariate analyses for ipsilateral breast tumor recurrence among early breast cancer patients.

\begin{tabular}{|c|c|c|c|c|}
\hline \multirow[b]{2}{*}{ Variables } & \multicolumn{2}{|c|}{ Univariate analysis } & \multicolumn{2}{|c|}{ Multivariate analysis } \\
\hline & HR $(95 \% \mathrm{CI})$ & $p$-Value & HR $(95 \% \mathrm{CI})$ & $p$-Value \\
\hline Age $\leq 40$ years (no versus yes) & $4.8(1.48-15.63)$ & 0.009 & $4.99(1.48-16.83)$ & 0.009 \\
\hline Resection margin (negative versus positive) & $3.85(1.26-11.75)$ & 0.018 & $3.85(1.21-12.27)$ & 0.023 \\
\hline HER2 (negative versus positive) & $5.3(1.84-15.28)$ & 0.002 & $7.03(2.1-23.48)$ & 0.002 \\
\hline $\mathrm{ALC} 1(>1479$ versus $\leq 1479$ cells $/ \mu \mathrm{l})$ & $11.2(1.46-88.6)$ & 0.02 & $9.13(1.17-71.55)$ & 0.047 \\
\hline Intraductal component (present versus absent) & $0.2(0.02-1.6)$ & 0.129 & & \\
\hline
\end{tabular}

HER2: Human epidermal growth receptor 2; ALC1: absolute lymphocyte count 3-5 months after radiotherapy; HR: hazard ratio; CI: confidence interval.

treatment results $(17,18)$. Therefore, in EBC patients for whom complete tumor resection is expected, it may be appropriate to evaluate the clinical impact of innate lymphopenia and the ability to overcome this condition.

Lymphopenia in EBC patients can predict IBTR independent of previously identified risk factors, such as young age, RM status, and HER2 receptor positivity (19). Therefore, sustaining lymphocyte levels through a reduction in physical or psychological stress may be effective in preventing IBTR among EBC patients treated with BCT (20). A nationwide population-based analysis on breast cancer survivors performed by Heo et al. reported that the overall frequency of psychological disorders such as depression, anxiety, and stress reaction/adjustment disorders peaked within one month after diagnosis (21). This can be related to disruptions in recovery from lymphopenia after $\mathrm{BCT}$, as shown in a report on the association between a high neutrophil-to-lymphocyte ratio and major depressive disorder (22). Therefore, active interventions for psychological stress may help in reducing IBTR.

This study has several limitations. First, we retrospectively examined a small number of patients whose data was collected 
over a long period of time. Second, it was not easy to estimate the cause of lymphopenia because detailed information regarding immune parameters such as information on lymphocyte subpopulations was absent. Nevertheless, this is the first study to demonstrate that lymphopenia is a potential predictor of IBTR after BCT in EBC patients.

Lymphopenia after BCT is a potential predictor of IBTR in EBC patients. Thus, IBTR could be reduced in young patients through the active management of psychological disorders, which are likely to occur throughout the disease course. The association between lymphopenia in EBC patients and IBTR should be investigated through large-scale retrospective studies or well-designed prospective studies.

\section{Conflicts of Interest}

There are no conflicts of interest to declare.

\section{Authors' Contributions}

OC was responsible for the conception and design. OC, MC, SKW, YSJ, and HY were responsible for the acquisition of date. OC and $\mathrm{MC}$ were responsible for the statistical analyses and interpretation. OC wrote the first draft of the manuscript. All Authors read and approved the final manuscript.

\section{Acknowledgements}

This research was supported by the Bio \& Medical Technology Development Program of the National Research Foundation (NRF) funded by the Korean government (MSIT) (NRF-2018M3A9E8 023860)

\section{References}

1 Arriagada R, Lê MG, Rochard F and Contesso G: Conservative treatment versus mastectomy in early breast cancer: Patterns of failure with 15 years of follow-up data. Institut gustave-roussy breast cancer group. J Clin Oncol 14(5): 1558-1564, 1996. PMID: 8622072. DOI: 10.1200/JCO.1996.14.5.1558

2 Blichert-Toft M, Rose C, Andersen JA, Overgaard M, Axelsson $\mathrm{CK}$, Andersen KW and Mouridsen HT: Danish randomized trial comparing breast conservation therapy with mastectomy: Six years of life-table analysis. Danish breast cancer cooperative group. J Natl Cancer Inst Monogr 11: 19-25, 1992. PMID: 1627427.

3 Fisher B, Anderson S, Bryant J, Margolese RG, Deutsch M, Fisher ER, Jeong JH and Wolmark N: Twenty-year follow-up of a randomized trial comparing total mastectomy, lumpectomy, and lumpectomy plus irradiation for the treatment of invasive breast cancer. N Engl J Med 347(16): 1233-1241, 2002. PMID: 12393820. DOI: $10.1056 /$ NEJMoa022152

4 Poggi MM, Danforth DN, Sciuto LC, Smith SL, Steinberg SM, Liewehr DJ, Menard C, Lippman ME, Lichter AS and Altemus RM: Eighteen-year results in the treatment of early breast carcinoma with mastectomy versus breast conservation therapy: The national cancer institute randomized trial. Cancer 98(4): 697-702, 2003. PMID: 12910512. DOI: 10.1002/cncr.11580
5 Veronesi U, Cascinelli N, Mariani L, Greco M, Saccozzi R, Luini A, Aguilar M and Marubini E: Twenty-year follow-up of a randomized study comparing breast-conserving surgery with radical mastectomy for early breast cancer. N Engl J Med 347(16): 1227-1232, 2002. PMID: 12393819. DOI: 10.1056/ NEJMoa020989

6 van Dongen JA, Voogd AC, Fentiman IS, Legrand C, Sylvester RJ, Tong D, van der Schueren E, Helle PA, van Zijl K and Bartelink H: Long-term results of a randomized trial comparing breast-conserving therapy with mastectomy: European organization for research and treatment of cancer 10801 trial. J Natl Cancer Inst 92(14): 1143-1150, 2000. PMID: 10904087. DOI: $10.1093 /$ jnci/92.14.1143

7 Kini V, Vicini F, Frazier R, Victor S, Wimbish K and Martinez A: Mammographic, pathologic, and treatment-related factors associated with local recurrence in patients with early-stage breast cancer treated with breast conserving therapy. International Journal of Radiation Oncol Biol Phys 43(2): 341-346, 1999. PMID: 10030259. DOI: 10.1016/S0360-3016(98) 00395-2

8 Johns N and Dixon JM: Should patients with early breast cancer still be offered the choice of breast conserving surgery or mastectomy? Eur J Surg Oncol 42(11): 1636-1641, 2016. PMID: 27665053. DOI: $10.1016 /$ j.ejso.2016.08.016

9 Poortmans P, Aznar M and Bartelink H: Quality indicators for breast cancer: Revisiting historical evidence in the context of technology changes. Semin Radiat Oncol 22(1): 29-39, 2012. PMID: 22177876. DOI: 10.1016/j.semradonc.2011.09.007

10 Venkatesulu BP, Mallick S, Lin SH and Krishnan S: A systematic review of the influence of radiation-induced lymphopenia on survival outcomes in solid tumors. Crit Rev Oncol Hematol 123: 42-51, 2018. PMID: 29482778. DOI: 10.1016/j.critrevonc. 2018.01.003

11 Sage EK, Schmid TE, Sedelmayr M, Gehrmann M, Geinitz H, Duma MN, Combs SE and Multhoff G: Comparative analysis of the effects of radiotherapy versus radiotherapy after adjuvant chemotherapy on the composition of lymphocyte subpopulations in breast cancer patients. Radiother Oncol 118(1): 176-180, 2016. PMID: 26683801. DOI: 10.1016/j.radonc.2015.11.016

12 Panet-Raymond V, Truong PT, McDonald RE, Alexander C, Ross L, Ryhorchuk A and Watson PH: True recurrence versus new primary: An analysis of ipsilateral breast tumor recurrences after breast-conserving therapy. Int J Radiat Oncol Biol Phys 81(2): 409-417, 2011. PMID: 21288654. DOI: 10.1016/j.ijrobp. 2010.05 .063

13 Grossman SA, Ye X, Lesser G, Sloan A, Carraway H, Desideri $\mathrm{S}$, Piantadosi S and Consortium NC: Immunosuppression in patients with high-grade gliomas treated with radiation and temozolomide. Clin Cancer Res 17(16): 5473-5480, 2011. PMID: 21737504. DOI: 10.1158/1078-0432.CCR-11-0774

14 Balmanoukian A, Ye X, Herman J, Laheru D and Grossman SA: The association between treatment-related lymphopenia and survival in newly diagnosed patients with resected adenocarcinoma of the pancreas. Cancer Invest 30(8): 571-576, 2012. PMID: 22812722. DOI: 10.3109/07357907.2012.700987

15 Ellsworth SG: Field size effects on the risk and severity of treatment-induced lymphopenia in patients undergoing radiation therapy for solid tumors. Advances Radiat Oncol 3(4): 512-519, 2018. PMID: 30370350. DOI: 10.1016/j.adro.2018.08.014

16 Ray-Coquard I, Cropet C, Van Glabbeke M, Sebban C, Le Cesne A, Judson I, Tredan O, Verweij J, Biron P, Labidi I, Guastalla J- 
P, Bachelot T, Perol D, Chabaud S, Hogendoorn PCW, Cassier P, Dufresne A, Blay J-Y, European Organization for R, Treatment of Cancer Soft $\mathrm{T}$ and Bone Sarcoma G: Lymphopenia as a prognostic factor for overall survival in advanced carcinomas, sarcomas, and lymphomas. Cancer Res 69(13): 5383-5391, 2009. PMID: 19549917. DOI: 10.1158/0008-5472.CAN-08-3845

17 Diehl A, Yarchoan M, Hopkins A, Jaffee E and Grossman SA: Relationships between lymphocyte counts and treatment-related toxicities and clinical responses in patients with solid tumors treated with pd-1 checkpoint inhibitors. Oncotarget 8(69): 114268-114280, 2017. PMID: 29371985. DOI: 10.18632/ oncotarget. 23217

18 Maltese M, Panni S, Lazzarelli S, Brighenti M, Negri F, Ratti M, Giganti MO and Passalacqua R: High baseline lymphocyte count is a predictive biomarker of prolonged time to progression in patients with advanced solid tumors receiving checkpoint inhibitors. J Clin Oncol 35(15_suppl): e14532-e14532, 2017. DOI: $10.1200 / J C O .2017 .35 .15 \_s u p p l . e 14532$

19 van der Leij F, Elkhuizen PHM, Bartelink H and van de Vijver MJ: Predictive factors for local recurrence in breast cancer. Semin Radiat Oncol 22(2): 100-107, 2012. PMID: 22385917. DOI: $10.1016 /$ j.semradonc.2011.12.001
20 Shi Y, Devadas S, Greeneltch KM, Yin D, Allan Mufson R and Zhou J-n: Stressed to death: Implication of lymphocyte apoptosis for psychoneuroimmunology. Brain Behav Immun 17(1): 18-26, 2003. PMID: 12615182.

21 Heo J, Chun M, Oh Y-T, Noh OK and Kim L: Psychiatric comorbidities among breast cancer survivors in south korea: A nationwide population-based study. Breast Cancer Res Treat 162(1): 151-158, 2017. PMID: 28062982. DOI: 10.1007/s10549016-4097-0

22 Demir S, Atli A, Bulut M, İbiloğlu AO, Güneș M, Kaya MC, Demirpençe Ö and Sır A: Neutrophil-lymphocyte ratio in patients with major depressive disorder undergoing no pharmacological therapy. Neuropsychiatr Dis Treat 11: 22532258, 2015. PMID: 26347335. DOI: 10.2147/NDT.S89470

Received May 24, 2019

Revised June 11, 2019

Accepted June 12, 2019 